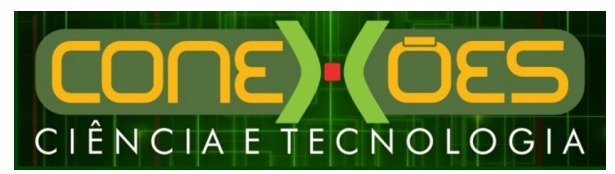

ESTUDO DE CASO NO IFCE MARACANAÚ ACERCA DAS CONTRIBUIÇÕES PROPORCIONADAS PELAS DISCIPLINAS PEDAGÓGICAS NA FORMAÇÃO DO FUTURO DOCENTE DE QUÍMICA

\title{
ESTUDO DE CASO NO IFCE MARACANAÚ ACERCA DAS CONTRIBUIÇÕES PROPORCIONADAS PELAS DISCIPLINAS PEDAGÓGICAS NA FORMAÇÃO DO FUTURO DOCENTE DE QUÍMICA
}

\author{
Jean Gleison Andrade do Nascimento ${ }^{1}$, Manuel Bandeira dos Santos Neto ${ }^{1}$, \\ Suyanne do Nascimento Almeida ${ }^{2}$, Felipe Alves Silveira ${ }^{1}$, \\ Pedro Hermano Menezes de Vasconcelos ${ }^{1}$ \\ ${ }^{1}$ Instituto Federal de Educação, Ciência e Tecnologia do Ceará (IFCE) \\ ${ }^{2}$ Secretaria de Educação Básica do Ceará (SEDUC) \\ $<$ jandradenascimento@gmail.com>.<manoelbandeirasn13@gmail.com> \\ <suyannenascimento@gmail.com>,<felipesilveiraquimica@gmail.com> \\ <pedro_hermano@yahoo.com.br> \\ DOI: 10.21439/conexoes.v12i3.1222
}

\begin{abstract}
Resumo. Este trabalho tem como objetivo compreender a importância das disciplinas pedagógicas para a formação dos licenciandos em Química, partindo do pressuposto de que as disciplinas pedagógicas não podem ser consideradas como simples extensões das reivindicações legais, propostas pelo currículo de cada licenciatura. O estudo foi realizado no IFCE - Campus Maracanaú com doze alunos, a partir do $6^{\circ}$ semestre do curso de Licenciatura em Química. A compreensão dessa problemática se norteou pelos procedimentos recomendados pela abordagem qualitativa de pesquisa, utilizando como estratégia a coleta de dados, através de questionário com questões abertas e exploratórias. Os resultados apontam que a consolidação da formação pedagógica advém do envolvimento e articulação entre teoria e prática e da mobilização dos saberes pedagógicos no cotidiano de trabalho. Constatamos, assim, que as disciplinas didático-pedagógicas são contribuidoras para a formação docente, uma vez que estas proporcionam ferramentas, metodologias e elementos que norteiam a prática do professor em sala de aula e também fora dela. $\mathrm{O}$ estudo apontou, ainda, que somente o conhecimento científico não se faz necessário e que para a formação do profissional professor também são necessários os saberes pedagógicos. Nesse contexto, as disciplinas didático-pedagógicas promovem uma reflexão sobre a docência e possibilita que a prática do professor seja um espaço contínuo de formação, tendo a prática como ponto inicial e final.
\end{abstract}

Palavras-chaves: Formação Pedagógica. Licenciatura em Química. Trabalho Docente

\section{CASE STUDY IN THE FEDERAL INSTITUTE OF EDUCATION, SCIENCE AND TECHNOLOGY OF CEARÁ-CAMPUS MARACANAÚ ON THE CONTRIBUTIONS PROVIDED BY THE PEDAGOGICAL DISCIPLINES IN THE TRAINING OF THE TEACHING FUTURE OF CHEMISTRY}

\begin{abstract}
The objective of this work is to understand the importance of pedagogical disciplines for the training of chemistry graduates, based on the assumption that pedagogical disciplines can not be considered as simple extensions of legal claims, proposed by the curriculum of each undergraduate degree. The study was carried out at the IFCE - Campus Maracanaú with twelve students, as of the 6th semester of the degree in Chemistry. The understanding of this problem was guided by the procedures recommended by the qualitative approach of research, using as strategy the data collection, through a questionnaire with open and exploratory questions. The results show that the consolidation of pedagogical training stems from the involvement and articulation between theory and practice and the mobilization of pedagogical knowledge in daily work. Thus, we find that the didactic-pedagogical disciplines are contributing to teacher education, since they provide tools, methodologies and elements that guide the teacher's practice in the classroom and also outside of it. The study also pointed out that only scientific knowledge is not necessary and that the formation of the professional teacher also requires pedagogical knowledge. In this context, the didactic-pedagogical disciplines promote reflection on teaching and enable the practice of the teacher to be a continuous space of formation, with practice as the starting and ending point.
\end{abstract}

Keywords: Pedagogical Training. Chemistry graduation. Teaching Work. 


\section{INTRODUÇÃO}

$\mathrm{O}$ contexto atual, marcado pelo desenvolvimento e pelas grandes transformações científicas, tecnológicas, sociais e culturais, tem repercutido, continuamente, em nosso cotidiano. As universidades, diante das funções que lhe são conferidas, são as mais requisitadas perante a sociedade para acompanhar tais mudanças que ocorrem na vida das pessoas e, nesse caso, os professores tornam-se protagonistas nas explicações das problemáticas sociais. Por esses motivos os mesmos no geral devem sempre aperfeiçoar seus conhecimentos, mediante a articulação entre ensino, pesquisa e extensão.

Ao admitirmos que a docência é uma atividade complexa, entendemos que esse exercício profissional exige uma preparação cuidadosa, a partir de estudos científicos, pedagógicos, métodos, técnicas, dentre outros aspectos que envolvem o processo ensino-aprendizagem. Essa preparação ocorre tanto em cursos de graduação e pós-graduação em instituições de ensino superior quanto na prática profissional, em seu contexto de trabalho.

Nessa compreensão, consideramos que a supervalorização dos conhecimentos específicos da área a ser exercida e a ausência dos saberes pedagógicos na formação de futuros professores acarretam uma formação acadêmica precária. A priori, as disciplinas pedagógicas, frequentemente, caracterizaram-se como uma coadjuvante na educação, pois, historicamente, o ensinar esteve sempre ligado à questão do domínio dos saberes específicos, onde imperava o pensamento de "quem sabe fazer sabe ensinar", ou o "professor bom já nasce feito". Para um leigo, ensinar parece ser fácil, pois se pensa que lecionar é adentrar em sala de aula e falar sobre um conteúdo que está em um livro elaborado por um especialista na área. Nesse sentido, compreendemos que o ensinar fomenta mais que isso, pois o ensino corresponde também a meios didáticos, ações pedagógicas e condições teórico-metodológicas, requerendo mais responsabilidades e esforços a fim de aprimorar as capacidades cognitivas e assimilação dos conteúdos por parte dos alunos (PIMENTA; ANASTASIOU, 2014).

A consolidação da formação pedagógica necessária para a realização do trabalho docente advém não somente pelos conteúdos explicados em sala de aula, mas também da prática, constituindo-se pela variedade de saberes que se fundamentam e se confirmam com as trocas de experiências do cotidiano com colegas de trabalho e com as vivências entre seus alunos. A formação docente, dessa maneira, está para além dos muros da Universidade, quando os estudantes de licenciaturas se propõem a participarem de congressos, projetos de pesquisa e extensão, seminários e debates, os quais lhe são proporcionados no decorrer de sua vida acadêmica (PIMENTA; ANASTASIOU, 2014).

No âmbito do conjunto de saberes que precisam ser apropriados pelos professores, destacam-se os saberes didáticos que analisam as relações entre o objeto de estudo, o discente e o docente. Eles relacionam os diversos tipos de dificuldades que podem ser enfrentadas no aprendizado pelos estudantes, as metodologias diversas de ensino junto com a prática de inovação do exercício docente, adaptando-se ao novo e eliminando a concepção de repetir o ensino que vem sendo feito há algum tempo. $\mathrm{O}$ conhecimento sobre as didáticas específicas torna-se um auxílio para a aprendizagem, sendo introduzido no âmbito educacional aos poucos (TARDIF, 2002).

Diante do exposto, esta investigação tem como objeto de estudo as disciplinas pedagógicas do curso de Licenciatura em Química do Instituto Federal de Educação, Ciência e Tecnologia do Ceará - Campus Maracanaú, localizado na região metropolitana de Fortaleza$\mathrm{CE}$, pois estas se caracterizam como norteadoras da prática docente do curso em questão de modo a solucionar ou minimizar os problemas que se apresentam no decorrer do processo ensino-aprendizagem no ensino superior.

As motivações que levaram a escolha deste tema advêm do fato de ser estudante do curso de Licenciatura em Química IFCE - Campus Maracanaú onde se adquiriu experiências de bolsista de IC (Iniciação Científica) durante dois anos e ID (Iniciação à Docência) durante um ano, complementando, assim, os saberes adquiridos nas disciplinas específicas do referido curso.

Considerando que o professor se forma não somente pela aquisição de conteúdos específicos de sua disciplina, mas também pelos saberes adquiridos nas disciplinas pedagógicas, e que estas proporcionam aos futuros professores a reflexão, problematização e transformação da sua própria ação pedagógica, elaboramos a seguir os seguintes questionamentos que nortearam esta pesquisa que são referentes aos objetivos específicos: De que forma as disciplinas pedagógicas contribuem para formação do futuro professor de Química? Quais os limites e possibilidades das disciplinas pedagógicas para a formação dos futuros professores? Qual a relação existente entre saberes pedagógicos e a prática docente do licenciando em Química?

Com base nesses questionamentos, este trabalho tem como objetivo principal compreender a importância das disciplinas pedagógicas para a formação dos licenciandos em Química. Como objetivos específicos, incluímos aspectos relacionados aos desafios e possibilidades desta formação dos futuros professores de Quí- 
ESTUDO DE CASO NO IFCE MARACANAÚ ACERCA DAS CONTRIBUIÇÕES PROPORCIONADAS PELAS DISCIPLINAS PEDAGÓGICAS NA FORMAÇÃO DO FUTURO DOCENTE DE QUÍMICA

mica; identificar as relações existentes entre os saberes pedagógicos e a prática docente do licenciando em Química, observando de que forma esta contribui ou não para a prática dos futuros professores, além de analisar o Projeto Político Pedagógico (PPP) do curso de Licenciatura em Química da instituição, levando em consideração sua proposta de formação pedagógica.

\section{FUNDAMENTAÇÃO}

Neste tópico realizaremos uma reflexão sobre a formação e o trabalho docente. Inicialmente, abordaremos o tema com base no referencial teórico estudado: Imbernón (2009), Tardif (2002), dentre outros e, em seguida, apresentaremos uma análise do Projeto Político Pedagógico do curso de Licenciatura em Química, Campus Maracanaú, tendo por base a Resolução CNE/CP N ${ }^{\circ}$ 01, de 18 de fevereiro de 2002, que trata da Formação de Professores da Educação Básica, em nível superior, curso de licenciatura, de graduação plena.

\subsection{Formação e Trabalho Docente}

Historicamente, a formação docente esteve vinculada a concepção de que ensinar referia-se à transmissão de conteúdos formais a estudantes considerados meros receptores de conhecimentos e experiências. Essa ideia, com as transformações sociais, políticas e econômicas da sociedade contemporânea, passou a ser considerada insuficiente diante das novas demandas. Nesse viés segundo Imbernón (2009) a formação atende a um papel que transcende o ensino que pretende uma mera atualização científica, pedagógica e didática e se transforma na possibilidade de possibilitar a criação de espaços de participação.

Com base nessa compreensão, o trabalho do professor ganha cada vez mais importância e passa a ter o desafio de oferecer aos estudantes os conhecimentos técnicos e científicos necessários para o exercício de uma futura profissão, mas também oportuniza vivências para que os mesmos adquiram a maturidade necessária para enfrentar os desafios do mundo em que vivem, consequentemente, fazerem suas próprias escolhas.

Para se alcançar as expectativas da educação no mundo atual é importante que o docente mobilize diferentes saberes os quais subsidiarão a formação do professor atingindo-o em sua totalidade, criando, dessa forma, uma identidade profissional com traços pessoais que correspondem a cada indivíduo (TARDIF, 2002 p. 86).

Os saberes profissionais definem-se como a capacidade com a qual um indivíduo tem de adquirir conhecimentos científicos, ou não científicos, que se inter- relacionam com o meio ao qual está inserido o indivíduo, neste caso, o ambiente escolar. De modo resumido, podemos afirmar que os saberes são decorrentes da influência das situações sociais e das práticas do cotidiano individual do professor.

São vários os saberes que fundamentam a formação e a prática do professor, quais sejam: temporais, construídos e dominados progressivamente durante um período de aprendizagem; experienciais, que são construídos na medida em que o profissional enfrenta as situações do cotidiano; didático-pedagógicos, que advêm de suas reflexões acerca de sua própria prática e o saber de sua área de conhecimento, a fim de obter o aperfeiçoamento específico para melhor atuar e para a construção do conhecimento ao interagir com seus alunos (TARDIF, 2002). Tais saberes são incorporados, ainda, em sua formação inicial, a fim de que o docente escolha qual desses saberes deva realmente ser usado pelos professores. Dessa maneira, os saberes permitem que os professores mobilizem-nos adequando-os da melhor forma possível em suas práticas cotidianas.

Considerando que a prática docente e os saberes mobilizados pelos professores em seu contexto de trabalho são inter-relacionados, percebemos como Freire (1996) que: “[...] ensinar não é só transferir conhecimentos" (p. 25), pois o ato de ensinar produz novos conhecimentos através da dialética teoria e prática, uma característica importante na práxis docente.

Com base nessa compreensão, o trabalho docente é caracterizado como trabalho interativo, social, ético e afetivo que requer saberes profissionais adquiridos na prática e pela prática, uma vez que produz resultados sobre o ser humano em suas relações sociais. Assim, podemos afirmar que o trabalho docente se constitui pela pluralidade de saberes, oriundos de fontes diferentes e produzidos em contextos institucionais e profissionais variados.

Fundamentado em saberes, o trabalho docente almeja objetivos de formação humana, por conseguinte é o que diferencia este das demais atividades educativas, pois seu objeto de estudo é o ser humano. Ele não abrange somente o ensino de conteúdos específicos, mas também é reflexo das mudanças da profissão do magistério, no decorrer de sua história, conforme considera Imbernón (2009):

[...] Hoje, a profissão já não é a transmissão de um conhecimento acadêmico ou a transformação do conhecimento comum do aluno em um conhecimento acadêmico. A profissão exerce outras funções: motivação, luta contra a exclusão social, participação, animação de grupos, relações [...] a formação do professor deve estar ligada a tarefas de 
ESTUDO DE CASO NO IFCE MARACANAÚ ACERCA DAS CONTRIBUIÇÕES PROPORCIONADAS PELAS DISCIPLINAS PEDAGÓGICAS NA FORMAÇÃO DO FUTURO DOCENTE DE QUÍMICA

desenvolvimento curricular, planejamento de programas e em geral melhoria da instituição (p.1417).

Nessa compreensão, o trabalho docente assume novos requisitos sobre a natureza, as condições e a organização do ensino, o que se diferencia como um desafio para os professores diante das transformações tecnológicas, da precarização das estruturas escolares e diante da violência, dos péssimos salários, da ausência de tempo para o desenvolvimento da pesquisa e de tantos outros dilemas a serem enfrentados na profissão docente.

Para o enfrentamento dessas adversidades no cotidiano escolar, consideramos que a formação docente não acontece somente pela aquisição de conhecimentos teóricos, mas também ocorre através de disposições adquiridas ao longo do seu trabalho e de sua formação, e que, dessa forma, não se restringe a um curso de graduação, entretanto abrange também um processo de formação continuada que acompanha o docente durante seu exercício profissional a partir dos saberes elaborados na experiência de sua caminhada, bem como da trajetória de formação e desempenho profissional.

Diante o exposto, consideramos que as discussões a respeito do trabalho docente são complexas e estão vinculadas à formação recebida nos cursos de graduação e ao contexto em que atuam, uma vez que produz resultados sobre o ser humano em suas relações sociais. Sendo assim, apresentaremos, a seguir, aspectos relacionados à formação pedagógica necessária à prática dos professores.

\subsection{A Proposta Pedagógica do Curso de Licencia- tura em Química do IFCE, Campus Maracanaú}

O Projeto Político Pedagógico (PPP) do Curso de Licenciatura em Química do IFCE, Campus Maracanaú foi estruturado em 2008, atendendo às determinações do Decreto $\mathrm{n}^{\mathrm{o}}$ 3462/2000, de 17 de maio de 2000, que autoriza os IFCEs ministrarem Ensino Superior voltados para formação pedagógica de docentes de disciplinas científicas e tecnológicas, bem como às exigências da LDB 9.294/96 e das Diretrizes Curriculares para a Formação de Professores da Educação Básica, em nível superior, curso de licenciatura, de graduação plena (Parecer CNE/CP 009/2001).

Associado ao aspecto legal, o Projeto Político Pedagógico do curso centra sua justificativa na demanda de professores para a educação básica na área de ciências da natureza e suas tecnologias no estado do Ceará que carece de profissionais dessa área, habilitados para o exercício da docência nas séries finais do Ensino Fundamental e no Ensino Médio (PPP, 2010).
Fundamentada em autores que discutem numa perspectiva crítica a formação de professores e os saberes da docência (Pimenta, 2004; Libâneo, 2002; Gauthier, 1998 e Shulman, 1988), a proposta pedagógica do curso visa a "formação do homem para o exercício da cidadania" (PPP, 2010, p. 19), por meio de um processo educativo crítico e reflexivo situado no contexto social.

A partir dessa concepção de formação humana, a proposta pedagógica do curso aponta a necessidade de reflexão sobre os referenciais políticos e curriculares que repercutem na escola a partir dos seguintes princípios: flexibilidade, interdisciplinaridade, contextualização, autonomia escolar, dentre outros que exigem uma mudança no perfil dos profissionais da educação.

As novas exigências em relação ao professor comentada na proposta pedagógica do curso referem-se à necessidade de se desenvolver o processo de aprendizagem dos alunos de diferentes formas, na perspectiva da autonomia, criatividade, consciência, crítica e ética. Diante disso, "formar o docente hoje supõe prepará-lo para a prática composta pela relação com os alunos, com o saber, com a didática, além, de exigir a construção de sua identidade profissional" (PPP, 2010, p.10).

Diante desse propósito maior que envolve o processo educativo, o entendimento no documento sobre a competência do professor não é a de dominar apenas os conteúdos essenciais de sua disciplina e possuir uma consciência crítica, mas sim de viabilizar "uma educação escolar que atenda ao desenvolvimento de habilidades e competências cognitivas dos seus alunos por meio das categorias do pensamento: interpretação, compreensão, análise, síntese e avaliação" (PPP, 2010, p.10).

Em vista de alcançar essa formação, o Projeto Político Pedagógico do curso propõe um currículo que articule teoria e prática e valorize as atividades acadêmicas, científicas e culturais vivenciadas na instituição, atendendo, assim, os critérios de organização da matriz curricular, bem como a alocação de tempos e espaços curriculares preconizados pela Resolução CNE/CP/2002. O PPP ressalta, ainda, “o caráter flexível, a articulação dos conteúdos, experiências interdisciplinares, a fim de não fragmentar a formação, assegurando a indispensável preparação profissional dos futuros professores" (p.17-18).

Analisando a proposta pedagógica, percebemos a importância da articulação entre o trabalho docente e a formação pedagógica, tendo em vista que o professor constrói sua profissão na medida em que exerce sua carreira. Sendo assim, o caráter pedagógico do processo formativo é importante para que o professor possa se desenvolver profissionalmente em sua prática e, consequentemente, criar seu jeito de ensinar caracterizando 
ESTUDO DE CASO NO IFCE MARACANAÚ ACERCA DAS CONTRIBUIÇÕES PROPORCIONADAS PELAS DISCIPLINAS PEDAGÓGICAS NA FORMAÇÃO DO FUTURO DOCENTE DE QUÍMICA

seu estilo, sua identidade. A formação pedagógica, assim, se faz necessária para o aprimoramento e para a conquista de melhores condições metodológicas que favoreçam cada vez mais o desenvolvimento cognitivo do aluno.

Nessa perspectiva, a formação Pedagógica é considerada um aspecto necessário para a atuação dos professores, tendo em vista que é um espaço de "reflexividade crítica sobre as práticas e de (re) construção permanente de uma identidade pessoal. Por isso, é tão importante investir a pessoa e dar um estatuto ao saber da experiência" (NÓVOA, 1997, p. 25).

Diante dessas reflexões, apresentaremos, a seguir, a metodologia utilizada na elaboração do trabalho e em seguida as análises dos questionários aplicados junto aos estudantes relacionando os dados coletados ao aporte teórico e discussões e as reflexões acerca da temática em questão.

\section{METODOLOGIA}

A compreensão dessa problemática orientou-se pelos procedimentos recomendados pela abordagem qualitativa de pesquisa que se desenvolve "numa situação natural, é rica em dados descritivos, tem um plano aberto e flexível e focaliza a realidade de forma complexa e contextualizada" (LUDKE; ANDRÉ 1986 p. 18). Este tipo de abordagem encontra no ambiente natural sua fonte direta de dados e o pesquisador o seu principal instrumento, fazendo-se necessário o contato direto e prolongado deste com o ambiente e, dessa forma, com a situação investigada.

No campo da abordagem qualitativa de investigação, optamos pelo estudo de caso, porque este permite atingir a totalidade do trabalho específico dos futuros professores, assim podendo obter um volume considerável de informações e, consequentemente, se aprofundar em seus aspectos. Nesse sentido, pretendemos analisar as questões que cercam a formação docente, a formação pedagógica e a prática docente e seus saberes, a fim de estudar um fenômeno sem separá-lo do seu contexto e, mais ainda, enfatizando a interpretação desse meio no qual o fenômeno está inserido, abrindo espaço para as diversas opiniões, representações, concepções divergentes ou não. Um estudo de caso deve proporcionar uma imagem a mais fiel e digna possível da realidade pesquisada em suas várias dimensões, dentro de sua real complexidade.

A proposta ora apresentada foi realizada no IFCECampus Maracanaú, especificamente, no curso de Licenciatura em Química. O referido curso é relativamente novo, pois iniciou suas atividades no mencionado campus no segundo semestre do ano de 2008. Os critérios de escolha dos sujeitos foram: o interesse dos mesmos em participarem da pesquisa e o fato de estarem matriculados pelo menos no $6^{\circ}$ semestre do curso, por considerarmos que a maioria dos entrevistados já tenha cursado grande parte das disciplinas pedagógicas da matriz curricular do curso, que no total são dez. A intenção foi ter a participação de discentes dos vários semestres ao qual o curso oferece a fim de proporcionar diversas opiniões e, assim, enriquecer cada vez mais o referido estudo, com opiniões divergentes ou não acerca da temática abordada. O grupo de estudantes, que participaram do estudo, foi definido durante a fase exploratória de campo, orientando-se pela livre adesão dos sujeitos.

Como estratégia de coleta de dados, aplicamos questionários com 12 sujeitos; o referido questionário versava sobre a importância das disciplinas pedagógicas para a formação dos licenciandos em Química. As atividades de investigação foram desenvolvidas em três etapas: A primeira é marcada pelo estudo da literatura sobre a formação e prática docente, a formação pedagógica e os saberes que sustentam estas práticas, a fim de fortificar o estudo com os embasamentos teóricos. Ainda nessa fase foi realizada a análise documental do Projeto Político Pedagógico do curso de Licenciatura em Química, Campus Maracanaú, tendo como base a Resolução CNE/CP No 01, de 18 de fevereiro de 2002, que trata da Formação de Professores da Educação Básica, em nível superior, curso de licenciatura, de graduação plena.

segunda foi caracterizada pela coleta de dados, realizada no IFCE - Campus de Maracanaú, junto a 20 alunos do Curso de Licenciatura em Química, dos quais somente 12 se propuseram a responder aos questionários. Na terceira etapa, foram analisados os dados com base no referencial teórico estudado e nas informações coletadas e descritas em seus detalhes de forma a permitir uma maior aproximação da realidade, pois “[...] os investigadores qualitativos tentam analisar os dados em toda a sua riqueza, respeitando, tanto quanto o possível, a forma em que estes foram registrados ou transcritos" (BOGDAN; BIKLEN, 1994, p. 48).

Assim, inicialmente, organizamos todo o material coletado, sistematizando os registros de campo. Em seguida, realizamos um confronto do material coletado com o aporte teórico, a fim de estabelecer conexões e relações dos dados, possibilitando a proposição de novas explicações, interpretações e discussões em paralelo com a temática abordada. 
ESTUDO DE CASO NO IFCE MARACANAÚ ACERCA DAS CONTRIBUIÇÕES PROPORCIONADAS PELAS DISCIPLINAS PEDAGÓGICAS NA FORMAÇÃO DO FUTURO DOCENTE DE QUÍMICA

\section{RESULTADOS E DISCUSSÕES}

\subsection{Os Caminhos da Formação Docente na Con- cepção dos Estudantes}

Este tópico trata da análise dos dados coletados no IFCE, Campus Maracanaú junto a 12 estudantes que estão entre o $6^{\circ}$ e $8^{\circ}$ semestre do curso de Licenciatura em Química. A seguir, serão apresentadas as concepções dos mesmos acerca de suas motivações pela escolha do curso, da formação docente recebida, enfocando a contribuição das disciplinas pedagógicas para sua futura atuação profissional.

\subsection{Perfil e Motivações}

O grupo dos sujeitos participantes deste estudo tratase de 12 estudantes do curso de Licenciatura em Química do IFCE, Campus Maracanaú. A maior parte (10) encontra-se nos $6^{\circ}$ e $7^{\circ}$ semestre e somente dois estão no $8^{\circ}$ semestre. Dos 12 sujeitos, oito são do sexo feminino e quatro do sexo masculino. Ao analisarmos os dados, percebemos que a maioria, num total de sete, possui experiência docente mesmo ainda cursando a graduação. Tal fato decorre das oportunidades que são oferecidas pela Instituição (IFCE), como a Monitoria e o PIBID (Programa Institucional de Bolsas de Iniciação à Docência) que proporcionam aos estudantes a vivência do papel e da importância da prática docente ao longo do curso. Dessa maneira, consideramos que a instituição de ensino tem o papel de garantir uma formação docente pautada na articulação entre teoria e prática, aspecto necessário para consolidar os conhecimentos adquiridos na Universidade. Nesse sentido, a Instituição cumpre com o seu papel, articulando ensino, pesquisa e extensão com a finalidade de formar profissionais críticos e criativos, capazes de construir com seu trabalho uma sociedade democrática e solidária (RIOS, 2009).

As oportunidades de aprendizagem oferecidas aos alunos pelo IFCE caracterizam-se como uma formação integral, pois possibilita aos mesmos atuarem em vários contextos, tanto a partir da monitoria e do PIBID, quanto na iniciação à pesquisa, através do PIBIC (Programa Institucional de Bolsas de Iniciação Científica), possibilitando que o aluno aperfeiçoe suas aprendizagens enquanto participam de congressos, palestras e seminários.

Essa concepção de formação é encontrada em Masetto (2010), quando afirma que a aula universitária transcende espaços corriqueiros proporcionando aprendizagens significativas no espaço onde o aluno possa vivenciar sua prática. $\mathrm{O}$ autor considera, ainda, que o principal de uma aula é a aprendizagem do aluno e que a interação entre os aprendizes (aluno e professor) pro- duza realmente o aprendizado.

Sabemos que a escolha por um curso universitário depende unicamente de cada indivíduo, mas também das observações, análises e comparações com outros cursos, com as profissões e profissionais, ao qual se pretende seguir. Ao questionar os estudantes sobre os motivos que o levaram a escolher a Licenciatura em Química tendo em vista essa colocação, percebemos que as respostas são variadas. Ademais, a escolha de certo curso repercute direta ou indiretamente na sociedade e nos indivíduos que nela se encontram, pois o mercado, de certa forma, direciona qual profissional e quais as habilidades que esse precisa atingir para ser contratado. Nesse sentido, Rios (2009) afirma que:

\section{[...] Entre os múltiplos papéis que desempenha- mos na sociedade ganha destaque o papel profis- sional. A profissão é indicativa do que fazemos no mundo/mercado do trabalho, da forma especí- fica de participação na construção da sociedade. $\mathrm{O}$ que somos está estreitamente ligado ao que faze- $\operatorname{mos}(\mathrm{p} .10)$.}

Para análise dos dados os sujeitos da investigação receberão a sua identificação através dos letras do A ao L, com a finalidade de preservar seu anonimato. Reforçado pela resolução 466/12 do Conselho Nacional de Saúde (CNS) que adota no seu âmbito a prevenção de procedimentos que asseguram a confidencialidade e a privacidade (BRASIL, 2012). Diversos são os fatores que influenciam na opção de uma pessoa por um curso que posteriormente estará relacionado ao que faremos. Nos depoimentos de alguns sujeitos observamos que um dos motivos pela escolha do curso referia-se a atuar como docente:

\begin{abstract}
A motivação da carreira docente, pois sempre quis ser professor e aliado com a disciplina de Química que é a minha paixão. Verificar como é prazeroso um bom entrosamento pelo fantástico mundo da Química e poder sentir como a mesma é misteriosa. Além de ter uma boa formação para atuar como graduado pelo IFCE usando dessa formação nas aulas do Ensino Médio (Aluno A).
\end{abstract}

Conforme o depoimento ilustrado, percebemos que o estudante sempre quis ser professor, no entanto, para que seu desejo se realizasse, buscou uma formação de nível superior, nos remetendo a ideia de que para atuar como docente não é necessário apenas ter vocação, e sim adquirir saberes específicos e pedagógicos numa instituição de ensino que proporcione condições para o futuro exercício do magistério.

Outro motivo destacado pelos estudantes foi o gosto pela Química. Três sujeitos disseram que ingressaram 
ESTUDO DE CASO NO IFCE MARACANAÚ ACERCA DAS CONTRIBUIÇÕES PROPORCIONADAS PELAS DISCIPLINAS PEDAGÓGICAS NA FORMAÇÃO DO FUTURO DOCENTE DE QUÍMICA

na Licenciatura por afinidade com essa disciplina, como podemos observar nos seguintes enxertos:

\begin{abstract}
A princípio não era o curso que almejava, mas já que passei na seleção quis cursar. Com o decorrer do tempo percebi a minha aptidão pelo curso e pretendo me formar. A Química sempre foi minha disciplina preferida (Aluno B).

Desde pequena sempre gostei de Química e isso acabou se aliando ao magistério (Aluno C).
\end{abstract}

Os depoimentos dos estudantes deixam entrever que suas escolhas não decorreram, inicialmente, da vontade de ser professor, e sim da afinidade pela área da Química. Por outro lado, os estudos e o envolvimento no curso terminaram proporcionando o interesse pela docência, vislumbrando boas expectativas em relação ao exercício do magistério.

Outro motivo apontado por um estudante refere-se à facilidade de entender os conteúdos de Química e à influência que recebeu de bons docentes, revelando que o exemplo de antigos professores favorece muitas vezes a escolha pelo magistério como profissão. É o que afirma o depoimento a seguir:

Um dos motivos que me levaram a ingressar no curso foi a facilidade com a disciplina no Ensino Médio e, principalmente, a influência de bons professores me fizeram escolher a licenciatura como carreira profissional (Aluno D).

Outros dois sujeitos destacaram que a intenção de atuar na indústria os levaram a ingressar no curso, entretanto, um desses afirma ter modificado suas expectativas em relação a sua escolha na medida em que cursava as disciplinas pedagógicas, tomando gosto pela profissão docente, como observamos no depoimento do aluno E:

Inicialmente, meu interesse em relação ao curso era totalmente voltado para trabalhar na indústria, porém, conforme as minhas experiências em sala com professores da área da Pedagogia pude tomar gosto pela prática da docência e com o passar do tempo descobri que estava no caminho certo e, atualmente, não me vejo em outra profissão, estou totalmente incluída no mercado de trabalho como docente (Aluno E).

Diante desse depoimento, não poderíamos deixar de considerar a importância das disciplinas pedagógicas para formação profissional dos estudantes, pois são elas que norteiam o trabalho docente, a exemplo dos estágios que oportunizam ao aluno conhecer a realidade na qual irá atuar. Conforme Masetto (2010):
[...] Assim tão importantes quanto à sala de aula onde se ministram aulas teóricas na universidade e os laboratórios, onde se realizam as aulas práticas, são os demais locais em que, por exemplo, se realizam as atividades profissionais daquele estudante (p.19).

Outros motivos para escolha do curso de Licenciatura em Química foram a experiência profissional como professor, além da oportunidade de conquistar um emprego, explicitados por dois estudantes A e B respectivamente: "Já lecionava, então, precisava de uma graduação" e "vasta oportunidades de estar empregado, já que faltam profissionais qualificados nessa área".

Diante dos aspectos que abrangem as motivações e o perfil dos sujeitos participantes da pesquisa para o ingresso no curso de Licenciatura em Química, faz-se imprescindível refletir acerca da formação recebida pelos estudantes, é o que será abordado a seguir.

\subsection{Formação Pedagógica do Curso: Primeiras Im- pressões}

No Projeto Pedagógico de Licenciatura em Química do IFCE- Campus Maracanaú, a prática pedagógica está proposta desde o início do curso, permeando toda a formação acadêmica dos estudantes. O curso recomenda em seu currículo uma formação profissional envolvida com o papel social do professor, entrelaçando as teorias existentes e a realidade do contexto educacional fazendo, desta forma, a articulação teoria e prática fundamental na formação do docente.

Em relação à formação pedagógica recebida durante o curso, os 12 estudantes participantes da pesquisa foram questionados se lembravam de ter cursado as disciplinas de Didática e Psicologia e todos eles responderam positivamente, entretanto, ao serem questionados se recordavam de outras disciplinas da área pedagógica, somente cinco responderam que sim, sendo que as citadas foram: História da Educação no Brasil ( $1^{\circ}$ Semestre) e Estrutura e Funcionamento do Ensino Básico ( $3^{\circ}$ Semestre). Diante disso, questionamos se o fato de os estudantes não citarem outras disciplinas foi por desconhecimento ou se somente destacaram aquelas mais significativas para sua formação acadêmica.

Em relação ao grau de satisfação da formação didático-pedagógica adquirida no curso de Licenciatura em Química, dos 12 respondentes, oito estudantes afirmaram se sentir satisfeitos e quatro afirmaram estar parcialmente insatisfeitos.

Os sujeitos também foram questionados quanto às expectativas iniciais em relação às disciplinas pedagógicas do curso de Licenciatura em Química e boa parte, 
ESTUDO DE CASO NO IFCE MARACANAÚ ACERCA DAS CONTRIBUIÇÕES PROPORCIONADAS PELAS DISCIPLINAS PEDAGÓGICAS NA FORMAÇÃO DO FUTURO DOCENTE DE QUÍMICA

num total de sete, afirmou que estas são muito importantes para o exercício da prática docente, como revela os seguintes depoimentos:

A expectativa foi focada no auxílio ao desenvolvimento do ensino nas escolas públicas, ou seja, um suporte ao trabalho docente e obter, também, um suporte teórico dos pesquisadores na área docente (Aluno F).

Que o conhecimento destas disciplinas possam me assessorar em um momento que eu precisar (Aluno $\mathrm{G})$.

As minhas expectativas é de que quando eu estiver atuando nesta área, ela possa me ajudar em situações que necessite de um conhecimento mais específico, que eu me sinta mais segura nas decisões importantes que eu possa tomar numa sala de aula (Aluno H).

A necessidade do aperfeiçoamento constante das metodologias de ensino foi apontada por apenas um sujeito, apesar de, a priori, considerar que as disciplinas pedagógicas não contribuiriam para sua formação. Foi somente com o exercício do magistério que as mesmas trouxeram significado para sua formação e atuação profissional:

No início achava desnecessário, sempre os mesmos assuntos e a mesma temática, mas quando comecei a atuar como docente, percebi a grande importância dessas disciplinas, pois as mesmas vão aperfeiçoando a nossa forma didática de ensinar (Aluno I).

É certo que para a ocorrência de uma aprendizagem significativa, além de professores e alunos comprometidos e espaços que contribuam para a aquisição do conhecimento, é também importante que os alunos sintam afeição pela disciplina a qual esteja estudando, pois é comprovado pela Psicologia que múltiplas são as formas de aprendizagem por parte dos alunos (GARDNER, 1995). Nesse sentido, perguntamos aos sujeitos quais as disciplinas pedagógicas, a qual eles tinham maior afinidade e percebemos que a Didática, citada por cinco, foi a que mais os estudantes gostaram:

Sem dúvidas, a disciplina de Didática. Pois ela trabalhou de forma completa a prática docente, que naquele momento era o que eu precisava para reconhecer que eu estava no curso certo, ela foi a primeira disciplina pedagógica que me fez começar a desenvolver a prática docente, pois a partir dela começaram a aparecer as oportunidades na área (Aluno B).
De acordo com o depoimento, percebemos que os conhecimentos adquiridos na disciplina de Didática foram importantes para que os estudantes tomassem gosto pela docência, se tornando um fundamento básico para a elaboração dos saberes pedagógicos na sua atuação como professor.

Para Libâneo (1994), a didática surge como um aspecto de grande importância na formação do professor, pois direciona os docentes em suas responsabilidades perante o ato de ensinar, contrariando a antiga ideia de que a função docente é meramente a de transmissão de conteúdos. Assim, a "didática e as metodologias específicas das disciplinas, apoiando-se em conhecimentos pedagógicos e científico-técnicos, são disciplinas que orientam a ação docente partindo das situações concretas em que se realiza o ensino" (p.33). Nessa compreensão, entendemos que o professor é um sujeito que propicia conhecimentos com bases científicas e que contribui através de suas reflexões para formação de cidadãos, onde suas atitudes perante os conteúdos ensinados e sua postura devem ser espelhados pelo contexto e pela realidade social a qual está inserido.

Outros quatro sujeitos afirmaram ter uma maior afinidade com a disciplina "Informática Educativa", mesmo não sendo especificamente considerada uma disciplina pedagógica. Diante disso, destacamos que o interesse pela Informática Educativa se dá justamente devido ao amplo espaço que as Tecnologias da Informação e Comunicação (TICs) estão tendo dentro do meio escolar e na sociedade em geral. Nesse quesito, o professor deve utilizar os aparatos tecnológicos a seu favor e utilizá-lo como uma ferramenta que auxilia o trabalho pedagógico do professor, por isso mesmo há a grande mobilização da EaD, principalmente, no Ensino Superior para que a tecnologia venha cada vez mais adentrar no campo educacional flexibilizando e revolucionando o ensinar e o aprender.

Outras disciplinas lembradas pelos estudantes foram Metodologia do Trabalho Científico (01), Psicologia da Aprendizagem (01) e Fundamentos Sócios Filosóficos e Políticos da Educação (01). Para uma melhor compreensão das contribuições das disciplinas pedagógicas para a formação profissional do futuro professor, abordaremos, a seguir, aspectos referentes às aprendizagens adquiridas nas referidas disciplinas.

\subsection{Aprendizagens e Contribuições das Discipli- nas Pedagógicas}

No tópico anterior discutimos a respeito das disciplinas pedagógicas que de alguma forma marcaram a vida acadêmica dos estudantes e como se dava sua relação com as mesmas. Em relação às aprendizagens adqui- 
ESTUDO DE CASO NO IFCE MARACANAÚ ACERCA DAS CONTRIBUIÇÕES PROPORCIONADAS PELAS DISCIPLINAS PEDAGÓGICAS NA FORMAÇÃO DO FUTURO DOCENTE DE QUÍMICA

ridas no âmbito das disciplinas pedagógicas, apresentamos a seguir cada uma dessas aprendizagens citadas pelos sujeitos e sua quantidade correspondente: elaboração de aulas (03); criação de metodologias para que as aulas se desenvolvessem de forma dinâmica (03); como agir em sala de aula (03); teorias e as leis que regem a educação (03); Assuntos relacionados à História da Educação, Ensino e Inclusão (01); importância da pesquisa para a formação docente $(01)$.

Diante da síntese apresentada, percebemos o reconhecimento dos estudantes em relação à contribuição das disciplinas pedagógicas para o futuro exercício da profissão docente. Os depoimentos a seguir ilustram a visão de cinco estudantes sobre a importância das mesmas para sua formação acadêmica:

\section{Melhor exploração da voz em sala de aula e maior confiança também (Aluno A).}

Aprendi como me comportar perante os alunos como também da existência de novas didáticas e metodologias para o processo de ensino e aprendizagem (Aluno G).

Ajudaram-me a entender os princípios, objetivos e estratégias para a organização, o desenvolvimento das aulas de Química e domínio da sala de aula, a relação professor/aluno, bem como o entendimento de como o aluno aprende (Aluno $\mathrm{H}$ ).

Contribuem para o norteamento da profissão de forma que possa deixar apto a exercer a carreira sem se preocupar com possíveis tropeços dessa natureza (Aluno D).

De acordo com os depoimentos, percebemos que os principais aspectos apontados dizem respeito ao comportamento em sala de aula e à maneira de ensinar. Um enfoque foi dado pelo aluno Q à relação professor-aluno que para Masseto (2010) deve ser pautada pelas questões afetivas e emocionais, contribuindo para o amadurecimento profissional do professor e para a autonomia do educando. O referido autor ainda acrescenta outros aspectos necessários ao trabalho docente:

...] Há um conjunto de habilidades que são fundamentais a serem desenvolvidas, como, por exemplo, aprender a se expressar e se comunicar como o outro colega, com o professor, com profissionais da área $[\ldots]$ trabalhar em equipe, fazer relatórios, realizar pesquisas [...] participar de grupos interdisciplinares ou de profissionais de áreas diferentes, redigir e apresentar trabalhos científicos (p.28).

Essas habilidades, apesar de serem indispensáveis para o desenvolvimento de uma boa aula, muitas vezes não são valorizadas nos cursos de formação profissional do professor que terminam priorizando o conteúdo específico de cada matéria "restando alguns poucos momentos para a parte prática" (MASETTO, 2010, p. 28).

Outros (03) sujeitos afirmaram que as disciplinas pedagógicas facilitaram o ensino de Metodologias que viessem a dar suporte a sua atuação como docente:

\section{Contribuíram com o ensino de metodologias que podem ser utilizadas para o desenvolvimento do ensino da Química, no foco em que os alunos pos- sam absorver com maior facilidade os conteúdos da disciplina em questão (Aluno L).}

Um sujeito afirmou que a contribuição das disciplinas pedagógicas foi a de compreender a educação através de fatos que ocorreram na história:

A compreensão da história da educação no decorrer dos séculos é promover mudanças no sistema de ensino de acordo com a necessidade da população local (Aluno K).

Para atuar na educação é importante que quem ingresse por este viés o faça por meio de uma formação crítica da realidade a qual irá atuar, por isso é importante estudar como se dá o processo de educação em um país, que concepções ela traz consigo, as lutas, as conquistas e o que pode ser feito para melhorar.

Por outro lado, outro sujeito afirmou que as disciplinas pedagógicas não contribuíram para sua atuação como docente devido ao seu interesse em ingressar na área da indústria. $\mathrm{Na}$ realidade, o referido estudante afirma não ter afinidade com a educação, no entanto, entrou em um curso de Licenciatura para se aprofundar mais nos conhecimentos específicos que a Química lhe oferece.

Diante do apresentado até o momento, percebemos que boa parte dos alunos consegue visualizar de maneira clara e objetiva qual a importância das disciplinas pedagógicas para sua formação docente. Como pesquisador e licenciando, percebemos que o que falta para que essas disciplinas sejam mais valorizadas é sua articulação com outras disciplinas do curso de Licenciatura em Química que ainda está incipiente, devido ao foco no conhecimento das áreas específicas.

Considerando esses resultados, apresentamos a seguir as considerações finais acerca deste estudo as quais nos permitem vislumbrar outros objetos de investigação, tendo em vista a complexidade do tema e sua relação com o "trabalho e formação docente" na área de Química. 
ESTUDO DE CASO NO IFCE MARACANAÚ ACERCA DAS CONTRIBUIÇÕES PROPORCIONADAS PELAS DISCIPLINAS PEDAGÓGICAS NA FORMAÇÃO DO FUTURO DOCENTE DE QUÍMICA

\section{CONSIDERAÇÕES FINAIS}

De acordo com os resultados analisados, constatamos que a consolidação da formação pedagógica do futuro professor advém do envolvimento e articulação entre teoria e prática, proveniente das disciplinas específicas e pedagógicas, bem como das múltiplas experiências adquiridas no âmbito do curso.

Especificamente em relação às disciplinas didáticopedagógicas, os dados revelam que estas são contribuidoras da formação docente, uma vez que proporcionam metodologias de ensino e estratégias de aprendizagem que norteiam a prática do professor em sala de aula e também fora dela. Diante disso, os alunos encontram no curso de Licenciatura em Química do IFCE, Campus Maracanaú, a certeza de que estarão amparados desde o início do curso, pois este é forjado para que os estudantes tenham uma formação sólida e qualificada capaz de atender a demanda da região onde se encontra.

Os resultados também apontaram que muitos graduandos modificaram sua forma de pensar sobre a formação pedagógica recebida, no momento em que atuaram como professores. Diante da necessidade de mobilizar os saberes pedagógicos e didáticos em sala de aula, lembraram-se do que foi aprendido na Universidade e perceberam que a formação docente transcende espaços corriqueiros, proporcionando aprendizagens significativas no espaço onde o aluno possa vivenciar sua prática.

O estudo revelou também que as constantes transformações do mundo atual, principalmente, diante das novas tecnologias, repercutem na formação e no trabalho docente, implicando novos desafios e novas possibilidades para a atuação desses profissionais. Os desafios são destacados pelos graduandos quando estes precisam utilizar os diversos saberes, habilidades e metodologias para melhor ensinar e se relacionar com seus alunos, ou seja, estabelecendo uma relação afetiva com a realidade dos mesmos a fim de conduzir de forma eficiente seu trabalho.

As possibilidades do trabalho docente são encontradas diante da complexidade da relação processo ensinoaprendizagem que busca o equilíbrio entre o que está escrito e o que se deve fazer, ou seja, na articulação entre a teoria e a prática. Assim, percebemos que as disciplinas didáticas - pedagógicas contribuem para a mudança do sistema educacional, no sentido em que cooperam para a melhoria da qualidade do ensino e, por conseguinte da aprendizagem e da boa formação dos futuros docentes.

O estudo apontou, ainda, que somente o conhecimento científico não se faz necessário e que para a formação do profissional professor é imprescindível os saberes pedagógicos. $\mathrm{E}$ tais saberes fazem parte de uma formação mais específica e que deve ser propiciada pe- las instituições de ensino. Nesse contexto, as disciplinas didático-pedagógicas condicionam a refletir sobre a docência e possibilita que a prática do professor seja um espaço contínuo de formação, tendo a prática como ponto inicial e final.

\section{REFERÊNCIAS}

BOGDAN, R.; BIKLEN, S. Investigação qualitativa em educação. Uma introdução à teoria e aos métodos. 1. ed. Porto: Porto Editora, 1994.

BRASIL. Lei de Diretrizes e Bases da Educação Nacional n. ${ }^{\circ}$ 9.396, de 20 de dezembro de 1996. Brasília, 1996.

Resolução No 466/96, Comissão Nacional de Ética Em Pesquisa. Brasília, 2012.

FREIRE, P. Pedagogia da Autonomia. 26. ed. São Paulo: Paz e Terra, 1996.

GADOTTI, M. Educação, cultura e desporto: Concepção e desafios para o século XXI. (escrito em 2000, por Moacir Gadotti, para a $1^{\mathrm{a}}$ Conferência Nacional de Educação, Cultura e desporto.). 2013. Disponível em: <http://www.virtual.ufc.br/solar/aula_ link/llesp/A_a_H/didatica_I/aula_01/imagens/03/ educacao_seculo_XXI.pdf> Acesso em: 28 Mar 2013.

GARDNER, H. Inteligências Múltiplas: a Teoria na Prática. 1. ed. Porto Alegre: Artes Médicas, 1995.

IFCE-CEARÁ. Projeto Político Pedagógico do curso de Licenciatura em Química. Maracanaú. [S.1.], 2010.

IMBERNÓN, F. Formação Docente e Profissional: formar-se para a mudança e a incerteza. 7 . ed. São Paulo: Cortez, 2009. v. 77.

LIBÂNEO, J. C. Didática. 1. ed. São Paulo: Cortez, 1994.

LUDKE, M. E.; ANDRÉ, M. E. D. A. Pesquisa em educação: abordagens qualitativas. 1. ed. São Paulo: EPU, 1986.

MASETTO, M. T. O Professor na Hora da Verdade: A prática docente no ensino superior. 1. ed. São Paulo: Avercamp, 2010. v. 1. P. 190.

NÓVOA, A. Formação de professores e profissão docente. In: Os professores e sua formação. Lisboa: Dom Quixote, 1997.

PIMENTA, S. G.; ANASTASIOU, L. G. C. Docência no Ensino Superior. 5. ed. São Paulo: Cortez, 2014. 
ESTUDO DE CASO NO IFCE MARACANAÚ ACERCA DAS CONTRIBUIÇÕES PROPORCIONADAS PELAS DISCIPLINAS PEDAGÓGICAS NA FORMAÇÃO DO FUTURO DOCENTE DE QUÍMICA

RIOS, T. A. Ética na docência Universitária: a ca-

minho de uma universidade pedagógica?Cadernos

Pedagogia Universitária. 1. ed. São Paulo: Editora da

Universidade de São Paulo, 2009.

TARDIF, M. Saberes docentes e formação

profissional. 2. ed. Rio de Janeiro: Vozes, 2002. 